\title{
Editorial: Vladimir Petrovich Filatov
}

It is noteworthy that this year marks the centenary of the birth of Vladimir Petrovich Filatov (18751956)-clinician, scientist, and Academician-one of the most famous ophthalmologists that Russia has produced. Born in the Ukraine and educated in Moscow, Filatov went to Odessa where he became director of the Ophthalmic Institute and eventually director of the Ukranian Experimental Institute for Eye Diseases and Tissue Therapy.

Filatov's name first became internationally known in connexion with corneal grafting. He shares the distinction with Elschnig of Prague of evolving a technique of keratoplasty as a practical surgical procedure. Furthermore, he popularized the preservation of grafts from cadaver eyes and, indeed, in 1934 was using them after they had been kept at a low temperature up to $4 \mathrm{I}$ hours after death, thus opening up a vast source of material. A second significant advance he made was to use lamellar grafts not for visual purposes but as a bed for a final penetrating graft. Meantime, he noted that the implantation of a graft tended to clear corneal opacities already present and on this observation he based his theory of the stimulation of tissues by the release of 'biogenic substances'. Thereby he introduced his technique of 'tissue therapy' by which it was claimed that a host of otherwise untreatable conditions varying from high myopia and pigmentary degeneration of the retina to optic atrophy could be improved by the topical or systemic injection of a large number of substances, the most popular of which were placental extracts or the subconjunctival implantation of placental tissue. This technique at one time enjoyed considerable popularity in the USSR and elsewhere in Europe, but, apart from any theoretical justification, most ophthalmologists have concluded that the technique is of little practical value in the treatment of these conditions.

This, however, cannot take away from its author the undoubted brilliance of his surgical achievements or the originality of his theoretical concepts. It is good to know that the Filatov Institute in Odessa still prospers under its present director, Dr N. A. Puchkovskaya. 